\title{
A inserção social da Pós-graduação em Serviço Social da Universidade do Estado do Rio Grande do Norte
}

\section{The Post-graduate social insertion in Social Work of the Rio Grande do Norte State University}

Fernanda Marques de Queiroz ${ }^{a}$

(D) https://orcid.org/0000-0002-1629-9305

Maria Ivonete Soares Coelho ${ }^{a}$

(D) https://orcid.org/0000-0001-6686-343X

Suzaneide Ferreira da Silva ${ }^{a}$

(D) https://orcid.org/0000-0001-6046-6193
Resumo: $O$ artigo visa discutir a inserção social do Programa de Pós-Graduação em Serviço Social e Direitos Sociais da Universidade do Estado do Rio Grande do Norte (UERN), contextualizando sua criação, trajetória, avanços e desafios, bem como as ações e experiências empreendidas na tríade ensino, pesquisa e extensão, com destaque para intervenção social.

Palavras-chave: Inserção Social. Pós-Graduação. Serviço Social. UERN.
Abstract: This article aims to discuss the social insertion of the Post-graduation Program in Social Service and Social Rights of UERN, contextualizing its creation, trajectory, advances, and struggles, as well as the actions and experiences undertaken in the education, research, and extension triad, with a spotlight on social intervention.

Keywords: Social Insertion. Post-graduate. Social Work. UERN. 


\section{Introdução}

Universidade do Estado do Rio Grande do Norte (UERN), caracte-
rizada pela interiorização do ensino de graduação, tem despen-
dido, nas últimas décadas, esforços no desafio da internalização da pós-graduação em nível stricto sensu, com a oferta de programas de pós-graduação ${ }^{1}$ (mestrado e doutorado) em diversas áreas do conhecimento. Nesse ínterim, o Programa de Pós-Graduação em Serviço Social e Direito Social — PPGSSDS, criado em 2013, com implantação em 2014, constitui-se um exemplo desses esforços.

O PPGSSDS passou, no interior do Rio Grande do Norte, em Mossoró, a suprir uma lacuna de formação em nível stricto sensu para assistentes sociais e profissionais de áreas afins, ao ofertar um mestrado acadêmico, com área de concentração em Serviço Social e Direitos Sociais, bem como oportunizar uma maior aproximação entre o espaço da produção do saber e diversos âmbitos sócio-ocupacionais, em especial do Serviço Social. Cabe ressaltar que Mossoró é uma cidade polo do oeste potiguar e atende, em grande medida, municípios circunvizinhos na demanda por formação em nível de graduação e pós-graduação, democratizando o acesso à universidade. No momento, temos 167 alunos de graduação em Serviço Social e 43 estudantes no PPGSSDS (com entrada anual com uma média de quinze estudantes e concorrência em torno de oitenta candidatos - na última seleção, em 2020, tivemos 93), os quais enfrentam os desafios cotidianos de pertencer a uma universidade estadual pública. Muitos, inclusive, precisam se deslocar diariamente de diferentes cidades e zonas rurais por meio de ônibus fretados e/ou custeados pelas prefeituras de suas cidades para realizarem seus estudos.

Na particularidade do PPGSSDS, em todas as seleções para ingressantes, temos recebido estudantes de diversas cidades.

Atualmente (2020), na UERN, existem vinte programas de pós-graduação, com a oferta de 26 cursos; destes, dezesseis mestrados acadêmicos, seis mestrados profissionais e quatro doutorados acadêmicos (UERN/PROPEG, 2019). 
Hegemonicamente, o perfil dos nossos egressos é de assistentes sociais que residem no interior e que atuam nas diversas políticas públicas, com destaque para saúde, assistência social e educação. O alcance social que o PPGSSDS tem conquistado é percebido por meio de seus egressos, uma vez que a maioria das dissertações defendidas dispõe sobre objetos vinculados à atuação profissional que têm dado retorno qualificado para atuação profissional no âmbito dessas políticas, considerando as particularidades territoriais de diversas cidades do interior do Nordeste. Cabe destacar que tanto em nível de produção de conhecimento como de intervenção profissional, o debate sobre essas políticas tem se dado em articulação com as temáticas prioritárias no âmbito da pesquisa e extensão do programa, sobretudo em torno da defesa dos direitos das mulheres, de crianças e adolescentes, da população negra e idosa. O PPGSSDS tem demonstrado, portanto, que um mestrado acadêmico não forma apenas para academia, mas também para intervenção qualificada nas mais diversas expressões da questão social.

O presente artigo tem por objetivo discutir sobre a inserção social do PPGSSDS, contextualizando sua trajetória, múltiplas ações e experiências no campo do ensino, pesquisa e extensão, com destaque para intervenção social.

Compreendemos que a universidade ocupa um lugar fundamental na realidade social, cuja função é contribuir com as mudanças que são necessárias para a construção de uma sociedade igualitária e democrática. Espera-se, assim, uma universidade socialmente referenciada que contribua para o enfrentamento das problemáticas socioeconômicas e políticas. Afinal, como diz Chaui, "a universidade é uma instituição social. Isso significa que ela realiza e exprime de modo determinado a sociedade de que faz parte. Não é uma realidade separada, e sim uma expressão historicamente determinada" (2016, p. 248). Ao tomar como objeto de análise o espaço educacional, em particular um programa de pós-graduação em uma universidade pública no interior do Nordeste, 
aumentamos a proximidade com nossa própria realidade, por intermédio da pesquisa nos diferentes aspectos da questão social, contribuindo para intervenção e alteração das relações sociais, pois, segundo Mészáros (1981, p. 260),

o complexo sistema educacional da sociedade é também responsável pela produção e reprodução da estrutura de valores dentro da qual os indivíduos definem seus próprios objetivos e fins específicos. As relações sociais de produção capitalistas não se perpetuam automaticamente.

Disputamos essa estrutura de valores por meio de uma intervenção crítica nas relações sociais. Nessa direção, buscamos discutir as experiências e perspectivas de inserções sociais do PPGSSDS.

\section{Programa de pós-graduação em Serviço Social e direitos sociais da universidade do estado do Rio Grande do Norte: breve apresentação}

O PPGSSDS foi autorizado pela Coordenação de Aperfeiçoamento de Pessoal de Nível Superior (Capes) em 2013 e teve suas atividades iniciadas em 2014. Constituem-se objetivos do PPGSSDS:

[...] a formação e qualificação de pesquisadores(as), docentes e profissionais, no âmbito do Serviço Social e áreas afins, focalizando os processos sociais que caracterizam a realidade brasileira e as particularidades da questão Social. Nessa perspectiva, pretende contribuir para a análise do Serviço Social, com ênfase nos direitos sociais. 0 curso objetiva ainda aprofundar o conhecimento sobre o Serviço Social e as situações concretas de materialização dos direitos sociais, particularmente na região Nordeste, fomentando a construção de conhecimentos sobre fenômenos sociais e culturais, mediante a articulação entre teoria-prática, na perspectiva da emancipação humana (PPGSSDS, 2013, p. 5). 
Esse programa tem como áreas de concentração Serviço Social e direitos sociais, os quais materializam-se a partir de três linhas de pesquisas: Serviço Social, direitos sociais e movimentos sociais; Serviço social, questão social e políticas públicas, e Serviço Social, feminismo e relações sociais patriarcais. ${ }^{2}$ Nota-se que tais estudos possibilitam tanto a inserção de temáticas investigativas, de ordens diversas, quanto o incremento de outras áreas de conhecimento - fator expressivo pelo número de profissionais da área do direito, da comunicação e outros segmentos que têm conseguido articular suas demandas investigativas com as linhas de pesquisas. Afere-se, portanto, ao curso uma inserção social para além do Serviço Social.

O PPGSSDS conta, atualmente, com catorze professores, dentre permanentes e colaboradores, todos vinculados e com atuação nos grupos de pesquisa e núcleos de extensão existentes na Fasso/UERN. Ressaltamos um diferencial no programa, que é a relação orgânica entre os grupos e linhas de pesquisa com os núcleos de extensão, inclusive com interação entre graduação e pós-graduação. Os grupos de pesquisa são: Grupo de Estudos e Pesquisas em Políticas Públicas (Geppp), Grupo de Estudos em Serviço Social, Trabalho, Direitos e Lutas Sociais (Gestuls) e Grupo de Estudos e Pesquisas sobre as Relações Sociais de Gênero e Feminismo (GEF). Já os núcleos de extensão são: Núcleo de Estudos sobre a Mulher Simone de Beauvoir (NEM), Núcleo de Estudos e Pesquisas sobre a Terceira Idade (Nepti) e Núcleo de Estudos e Ações Integradas na Área da Criança e do Adolescentes (Necria).

O Grupo de Estudos e Pesquisa em Políticas Públicas, criado em 2004, congrega pesquisadores em torno das reflexões/produções teóricas e empíricas que perpassam a relação Estado e sociedade, as múltiplas expressões da questão social e, particularmente, as áreas temáticas das políticas públicas e sociais, dos direitos sociais e de cidadania, da proteção e seguridade social, do desenvolvimento e da avaliação de políticas

2 Ver Relatório de dados enviados do Coleta, 2018b/Plataforma Sucupira. 
públicas e sociais, bem como de temas emergentes e transversais, pautados nas relações de igualdade e na diversidade humana, em suas diferentes expressões de classe, gênero, raça/etnia, orientação sexual e geração. O Grupo de Estudos em Serviço Social, Trabalho, Direitos e Lutas Sociais, criado em 2014, originou-se a partir de estudos relacionados às temáticas da ética, direitos humanos, lutas e movimentos sociais, assim como das discussões sobre o mundo do trabalho, direitos sociais e formação profissional, com produções teóricas sobre o estágio curricular, o trabalho de assistentes sociais e o projeto ético-político do Serviço Social. O Grupo de Estudos e Pesquisas sobre as Relações Sociais de Gênero e Feminismo, criado em 2010, por sua vez, debate e elabora sobre as temáticas das relações patriarcais de gênero/sexo e as diversas expressões das desigualdades sociais entre homens e mulheres na sociedade, com ênfase na questão das violências praticadas contra as mulheres e movimento feminista. Objetiva, além disso, estimular estudos e pesquisas em torno da trajetória e da teoria do feminismo como sujeito político das mulheres. Ao mesmo tempo, estimula a socialização das experiências de pesquisas interdisciplinares, possibilitando a troca de informações entre pesquisadoras em diferentes níveis de formação.

Os três núcleos de extensão, no que lhes diz respeito, como suas próprias designações já demonstram, realizam ações voltadas, prioritariamente, para a defesa dos direitos das mulheres, LGBTs, população negra, idosos, crianças e adolescentes, constituindo espaços privilegiados de práticas interventivas, assim como a construção de conhecimentos nessas áreas temáticas, de modo a estabelecer a integração entre universidade e sociedade.

Neste sentido, os grupos de pesquisa e os núcleos de extensão garantem a indissociável articulação entre ensino, pesquisa e extensão. Incorpora-se, à luz disso, áreas centrais para apreensão das múltiplas expressões da questão social, tal qual formas de intervenção que contribuam para uma formação plural, assegurando a direção social estratégica do projeto profissional do Serviço Social. 


\section{Inserção social do PPGSSDS/UERN: experiências e perspectivas}

A inserção social da pós-graduação como elemento de avaliação denota, com base na compreensão da Capes, uma responsabilidade social e deve, assim, não apenas melhorar a ciência, mas também melhorar o país (Ribeiro, 2007). Esse elemento avaliativo tem sido perseguido pelo PPGSSDS, muito mais como compromisso político com a formação de qualidade, socialmente referenciada, do que como exigência oficial para processos avaliativos, uma vez que se constitui em elemento norteador da articulação ensino-pesquisa-extensão.

Tal afirmação vem ilustrada por um conjunto de atividades desenvolvidas a partir da articulação das esferas do ensino, da pesquisa e da extensão realizadas. Integra-se docentes e discentes de graduação e da pós-graduação, com presença marcante no campo da materialização das políticas públicas e formação de seus agentes, bem como dos movimentos sociais nos municípios de atuação da UERN.

A inserção social se materializa, em especial, por intermédio dos núcleos de extensão. O Núcleo de Estudos sobre a Mulher Simone de Beauvoir (NEM), responsável por fomentar o debate sobre a condição das mulheres na sociedade, enfatiza as discussões a respeito da violência contra as mulheres, divisão sexual do trabalho, assédio e organização política feminista. Como exemplo disso, destacamos a atuação constante do NEM junto à rede de prevenção e combate à violência contra a mulher, com assessoria e parceria junto ao juizado da violência doméstica e familiar contra a mulher, defensoria pública, varas da família, ministério público e práticas jurídicas das universidades. O NEM presta, ainda, formação continuada a grupos de mulheres e movimentos feministas, promove debates, articula e organiza ações em torno do calendário feminista, com destaque para o 8 de março e o 25 de novembro. ${ }^{3}$

3 Dia Mundial de Combate à Violência contra a Mulher. 
O Núcleo de Estudos e Pesquisas sobre a Terceira Idade (Nepti) fomenta debates sobre a pessoa idosa; atua junto ao Conselho Municipal e Estadual do Idoso; entidades socioassistenciais voltadas para o envelhecimento e realiza cursos de capacitação sobre os direitos dos idosos, ministrados para conselheiros, além de ações de combate à violência contra este segmento. O Nepti também desenvolve ações sistemáticas de assessoria à política de assistência social em diferentes municípios.

Por fim, o Núcleo de Ações Integradas na Área da Criança e Adolescentes (Necria) desenvolve ações na área da infância e adolescência, bem como capacitação para conselheiros tutelares e educadores sociais. Como exemplo da sua atuação, citamos o projeto realizado com o Centro Educacional de Mossoró e Fundação da Criança e do Adolescente. O projeto atende jovens adolescentes que se encontram em regime de internação como medida privativa de liberdade; atinge em média quinze famílias, perfazendo um número aproximado de duzentas pessoas de grupos comunitários na microrregião. Além desse projeto, o Necria possui a Rádio Zapping, com programas semanais que tratam temáticas sobre criança e adolescentes, e o Cine Necria, voltado para debates de filmes que abordam a temática do núcleo, sempre subsidiados pela leitura de textos.

Outra temática de inserção do PPGSSDS são as relações étnico-raciais e o combate ao racismo, que ocorre por meio de pesquisas e ações ${ }^{4}$ que contribuíram significativamente para dar suporte à implantação das cotas étnico-raciais no âmbito da UERN, ${ }^{5}$ com o estabelecimento, inclusive, de Comissão de Heteroidentificação. ${ }^{6}$ O PPGSSDS foi o primeiro programa, em 2019, a incorporar em sua seleção cotas étnico-raciais e promove constantemente debates sobre racismo na universidade.

4 Sessões temáticas Luiza Main do Grupo de Estudos e Pesquisas em Políticas Públicas; reuniões e assessoria à gestão da UERN (reitoria e pró-reitoria de ensino de graduação) sobre o tema e participação no Núcleo de Estudos Afro-Brasileiros (Neab).

5 Lei Estadual no 10.480/2019 de 30 jan. 2019.

6 Portaria no 005/2020 - Consepe UERN. 
Outra expressão da inserção social do PPGSSDS ocorre pela participação de docentes e discentes na direção da Associação Brasileira de Ensino e Pesquisa em Serviço Social (Abepss), na coordenação dos grupos temáticos de pesquisa da Abepss, no Conselho Regional de Serviço Social (Cress), além de conselhos municipais de políticas públicas (saúde, assistência social, idoso). Nacionalmente, também tivemos uma docente representando o Conselho Federal de Serviço Social no Conselho Nacional de Combate à Discriminação e Promoção dos Direitos de Lésbicas, Gays, Bissexuais, Travestis e Transexuais, no período de 2018 a 2019, quando o mesmo foi extinto por meio do Decreto no 9.759, natureza do decreto e data de emissão.

A inserção social do PPGSSDS também se materializa a partir de três elementos básicos: a interiorização e a capilaridade de proveniência de seus estudantes; as pesquisas e ações interventivas, resultantes do processo formativo no programa protagonizado por docentes e discentes, e o conhecimento produzido e disseminado.

Nessa perspectiva, apontamos que os estudantes do programa são, basicamente, provenientes de instituições públicas de ensino superior localizadas no Nordeste ${ }^{7}$ - em particular no Rio Grande do Norte - , de cursos presenciais, com ênfase nos cursos de Serviço Social, tendo como principal área afim o curso de direito. As pesquisas e ações interventivas têm base nas realidades locais, com impacto direto na construção de compreensões sobre o ambiente, entendido aqui como espaços municipais de inserção dos discentes, em vista do conhecimento empírico e reflexões científicas sobre as múltiplas realidades que conformam as expressões da questão social.

Particularmente sobre as pesquisas, os temas e as dissertações defendidas circulam, de forma orgânica, junto aos tópicos nucleados

\footnotetext{
PPGSDS demonstra capilaridade ímpar com alunos provenientes especialmente dos estados do Rio Grande do Norte, Ceará e Paraíba, com atuação em municípios de pequeno e médio porte, cujas pesquisas e dissertações produzem conhecimento que dão conta das expressões da questão social no território do sertão, do semiárido nordestino.
} 
nos grupos de pesquisa e núcleos de extensão, com foco nas questões de gênero, geração e raça/etnia, bem como nas políticas públicas que conformam a seguridade social e os direitos sociais, dando consistência e materialidade à inserção social do PPGSSDS.

\section{Considerações finais}

A existência de um programa de pós-graduação em uma universidade estadual no interior do Nordeste constitui-se por si só um grande desafio. Desafio que se adensa ao compromisso do projeto profissional de ser socialmente referenciado, por meio de sua inserção social com respostas concretas às manifestações da questão social.

A inserção social é prioritária no PPGSSDS, não sendo, portanto, uma dimensão secundária. A sua importância é revelada pela qualidade de resposta à realidade social, seja pela capacidade de construir indicativos, produzir conhecimentos críticos e ações extensionistas, seja pela intervenção qualificada pela práxis profissional de nossos egressos nas diferentes políticas públicas e na defesa dos direitos.

Por fim, na direção aqui apontada, a inserção social não é compreendida como uma sobrecarga de trabalho para professores e estudantes, nem como uma espécie de desvio em relação às tarefas que seriam consideradas propriamente essenciais à pós-graduação. A inserção social dá vida e sentido ao trabalho. A pesquisa e a produção de conhecimento só adquirem sentido quando conectadas com a realidade, retornando em respostas qualificadas e condizentes com o nosso projeto profissional. Assim, o programa prima por contribuir com a defesa e a ampliação dos direitos, sem perder de vista um horizonte emancipatório para a sociedade.

Dessa forma, a inserção social do PPGSSDS dá materialidade ao seu objetivo, que é aprofundar e compreender as situações concretas de materialização dos direitos sociais. Para tanto, por meio da articulação 
entre teoria e prática, buscamos formar profissionais críticos, propositivos e criativos para atuar tanto no nível da dimensão interventiva, quanto acadêmica.

\section{Referências}

CAPES. APCN do Programa de Pós-graduação em Serviço Social e Direitos Sociais/Mestrado Acadêmico, Mossoró, UERN. 2013.

CAPES. Ficha de avaliação quadrienal (2013-2017) do Programa de Pós-Graduação em Serviço Social e Direitos Sociais. Brasília, 2018a.

CAPES. Relatório de dados do Programa de Pós-Graduação em Serviço Social e Direitos Sociais. Coleta Capes/Plataforma Sucupira, 2018b.

CHAUI, Marilena de Souza. Ideologia e educação. Educação e Pesquisa, São Paulo, v. 42, n. 1, p. 245-258, 2016. Disponível em: www.scielo.org/brrhnw. Acesso em: 7 abr. 2020.

MÉSZÁROS, István. A teoria da alienação. Rio de Janeiro: Zahar Editores, 1981.

RIBEIRO, Renato Janine. Inserção social. Disponível em: https://www.capes.gov.br/images/ stories/download/artigos/Artigo_23_08_07.pdf. Acesso em: 28 fev. 2020.

RIO GRANDE DO NORTE. Lei Estadual no 10.480/2019 de 30 de janeiro de 2019. Dispõe sobre a instituição de cotas e sobre $o$ argumento de inclusão regional nos processos seletivos de vagas iniciais da Universidade do Estado do Rio Grande do Norte - UERN, para alunos egressos da rede pública de ensino, revoga a Lei no 8.258/2002 e a Lei no 9.696/2013, fixando outras providências.

UERN. Plano institucional de desenvolvimento da pós-graduação stricto sensu da UERN 2019-2026. Mossoró: UERN, 2019. Disponível em: http://www.uern.br/controledepaginas/ propeg-posgraduacao-mestrado-doutorado/arquivos/2832plano_institucional_de_ desenvolvimento_da_pa\%E2\%80\%9Cs_graduaa\%E2\%80\%A1a\%C6\%92o.pdf. Acesso em: 8 fev. 2020.

UERN. Portaria no 005/2020 - Consepe/UERN. Regulamenta o procedimento de heteroidentificação complementar à autodeclaração dos candidatos pretos, pardos e indígenas, para fins de preenchimento das vagas reservadas para cota social nos Processos Seletivos de Vagas Iniciais (PSVI) da Universidade do Estado do Rio Grande do Norte - UERN. 


\section{Sobre as autoras}

Fernanda Marques de QueIroz - Doutora em Serviço Social. Professora da Faculdade de Serviço Social e do Programa de Pós-Graduação em Serviço Social e Direitos Sociais da Universidade do Estado do Rio Grande do Norte.

E-mail: fernandamarquesdequeiroz@gmail.com

Maria Ivonete Soares Coelho - Doutora em Ciências Sociais. Professora do Programa de Pós-Graduação em Serviço Social e Direitos Sociais da Universidade do Estado do Rio Grande do Norte.

E-mail: lunasoares@uol.com.br

Suzaneide Ferreira da Silva - Doutora em Ciências Sociais, professora do programa de pós-graduação em Serviço Social e Direitos Sociais.

E-mail: suzaneidemenezes@gmail.com 